\title{
Comprehensive review of the evidence regarding the effectiveness of community-based primary health care in improving maternal, neonatal and child health: 6. strategies used by effective projects
}

\author{
Henry B Perry ${ }^{1}$, Emma Sacks ${ }^{1}$, \\ Meike Schleiff ${ }^{1}$, Richard \\ Kumapley², Sundeep Gupta ${ }^{3}$, \\ Bahie M Rassekh ${ }^{4}$, \\ Paul A Freeman ${ }^{5,6}$
${ }^{1}$ Department of International Health, Johns Hopkins Bloomberg School of Public Health, Baltimore, Maryland, USA
${ }^{2}$ UNICEF, New York, New York, USA
${ }^{3}$ Medical epidemiologist, Lusaka, Zambia
${ }^{4}$ The World Bank, Washington, District of Columbia, USA
${ }^{5}$ Independent consultant, Seattle, Washington, USA
${ }^{6}$ Department of Global Health, University of Washington, Seattle, Washington, USA

Background As part of our review of the evidence of the effectiveness of community-based primary health care (CBPHC) in improving maternal, neonatal and child health $(\mathrm{MNCH})$, we summarize here the common delivery strategies of projects, programs and field research studies (collectively referred to as projects) that have demonstrated effectiveness in improving child mortality. Other articles in this series address specifically the effects of $\mathrm{CBPHC}$ on improving $\mathrm{MNCH}$, while this paper explores the specific strategies used.

Methods We screened 12166 published reports in PubMed of community-based approaches to improving maternal, neonatal and child health in high-mortality, resource-constrained settings from 19502015. A total of 700 assessments, including 148 reports from other publicly available sources (mostly unpublished evaluation reports and books) met the criteria for inclusion and were reviewed using a data extraction form. Here we identify and categorize key strategies used in project implementation.

Results Six categories of strategies for program implementation were identified, all of which required working in partnership with communities and health systems: (a) program design and evaluation, (b) community collaboration, (c) education for community-level staff, volunteers, beneficiaries and community members, (d) health systems strengthening, (e) use of community-level workers, and (f) intervention delivery. Four specific strategies for intervention delivery were identified: (a) recognition, referral, and (when possible) treatment of serious childhood illness by mothers and/or trained community agents, (b) routine systematic visitation of all homes, (c) facilitator-led participatory women's groups, and (d) health service provision at outreach sites by mobile health teams.

Conclusions The strategies identified here provide useful starting points for program design in strengthening the effectiveness of CBPHC for improving $\mathrm{MNCH}$.

In recent decades, much of the funding for global health has concentrated on technical cooperation pertaining to strengthening narrowly focused vertical programs, such as control of HIV, malaria and tuberculosis, and expanding immunization coverage. However, in order to accelerate progress in the reduction of readily preventable deaths of children and mothers, there have been calls for more direct funding for integrated maternal and 
child health programs [1], health systems strengthening [2], integration of key interventions via a continuum of care [3,4], and stronger community participation [5]. However, none of these calls have sufficiently emphasized the importance of strengthening community-based service delivery strategies for accelerating progress by achieving high levels of coverage of evidence-based interventions. Too often, attention has been focused on the technical aspects of interventions rather than on the strategies and support systems that are needed to achieve high levels of population coverage.

Previous reviews have highlighted family and community practices that are important for maternal, newborn and child health [6] as well as specific technical interventions that can be provided in communities [7-10], but none have to date focused specifically on the implementation strategies that effective projects have used. This paper summarizes the various approaches used by the programs, projects and studies (hereafter referred to as projects) whose effectiveness has been assessed and included in a comprehensive database.

\section{METHODS}

We conducted a comprehensive review of the effectiveness of community-based primary health care (CB$\mathrm{PHC}$ ) in improving maternal, newborn and child health (MNCH) by reviewing 12186 published reports of community-based programs for improving $\mathrm{MNCH}$ in low- and middle-income countries. 552 of these reports qualified. An additional 148 reports were identified from the "grey" literature (documents publicly available on the internet) and books. A total of 700 assessments were included in this review. A full description of the search strategy and creation of the database is available elsewhere [11].

Of particular importance for this paper is that a data extraction form was designed to capture as much information as possible in the document containing the project's assessment that describes the project strategies and what role the community played. We did not attempt to force any strict definition of the term "community" in the analysis of the findings since there was no uniform definition used in the projects or by the reviewers. By strategies we mean the activities that these projects used to make the intervention effective - to plan the project, engage partners (including the community), implement the project, engage in associated activities not directly related to intervention delivery, and evaluate the project. The data extraction forms used to collect information from the assessments were designed to capture the available information regarding strategies used for project implementation. In particular, open-ended descriptions of project implementation were completed by reviewers.

A copy of the data extraction form is contained in Online Supplementary Document of the above-mentioned paper [11]. The form allows for open-ended as well as close-ended responses related to strategies and community engagement. Data were extracted from each assessment by two independent reviews and a third reviewer resolved any differences between the first two reviews.

The maternal, neonatal and child health database was searched carefully to identify all information that described the strategies that were used by projects. All available evidence in the database regarding strategies for project implementation was reviewed by reviewing all the open-responses individually and summarizing common themes as well as by adding up the number of responses to close-ended questions.

\section{RESULTS}

We identified six categories of strategies used by the projects in our database: (a) program design and evaluation, (b) community collaboration, (c) education for community-level staff, volunteers, beneficiaries and community members, (d) health systems strengthening, (e) use of community-level volunteers and workers (hereafter referred to as community health workers, or CHWs), and ( $\mathrm{f}$ ) intervention delivery. Table 1 summarizes these strategies. The strategies were not mutually exclusive and most projects used at least several of these strategies and, in fact, some of the strategies fit into several categories (eg, participatory women's groups).

\section{Strategies for program design and evaluation}

Strategies for project design and evaluation shown in Table 1 often included baseline and endline knowledge, practice and coverage (KPC) population-based household surveys. These made it possible to measure changes in intervention coverage in the program population as well as changes in childhood nutri- 
Table 1. Summary of strategies used by CBPHC projects to improve child health

\section{Category of Stratiegy}

Program design and evaluation
SPEClFic STRATEgI

Knowledge, practice and coverage (KPC) household surveys

Participatory Rural Appraisal (PRA)

Village rosters of beneficiaries

Census-taking

Disease surveillance (based on information provided by community-based workers and communities)

Prospective registration of vital events (pregnancies, births and deaths)

Retrospective mortality assessment (based on maternal birth histories)

Determination of cause of death from verbal autopsies

Engagement of communities in planning and evaluation

Community engagement

Collaboration with or formation of village health committees and/or collaboration with local leaders

Formation and/or support of women's groups

Sharing locally obtained health-related data with the community

Participatory Rural Appraisal (PRA)

Formation and/or support of microcredit programs for women

Involvement of older family members (men and grandparents/mothers-in-law)

Education of community-level staff, Social marketing (media campaigns, posters, radio, etc.)

volunteers, beneficiaries and community Skits, stories and games for health education messages

members in general

Peer-to-peer education (volunteer mothers visiting neighbors with targeted health messages)

Education of grandmothers

Positive deviance inquiry

Training of trainers/cascade training

Identification of cases of childhood illness in need of referral

Strengthening referral system

Strengthening of quality of care at referral facility

Strengthening of supervisory system

Strengthening logistics/drug supply system

Training of providers at primary health center

Training of community-level health care providers

Use of community health workers

Intermittent use of minimally trained volunteers for highly specific, targeted activities

Use of volunteers for regular ongoing activities

Use of trained and paid workers with 1-11 months of training

Use of trained and paid workers with 1 year of training

Community case management

Home visits

Participatory women's groups

Provision of health services at community outreach points by mobile teams from peripheral facilities

Intervention delivery

tional status as determined by anthropometry. Oftentimes, community members served as interviewers or collaborators for these surveys. In some projects, Participatory Rural Appraisal (PRA), an approach that incorporates the viewpoints of local people in the planning and management of development projects, was used to guide project planning or evaluation.

Various approaches were used to determine the beneficiary population (usually mothers, including pregnant women, and their young children) such as household censuses carried out by the project in collaboration with community members or the development of village rosters of beneficiaries. Sometimes projects included a disease-surveillance component using information provided by community-based workers and communities. Examples are surveillance for acute flaccid paralysis (to identify possible cases of polio) and for other vaccine-preventable diseases such as neonatal tetanus and measles. Some projects measured changes in mortality directly, either through prospective vital events registration as in Care Group projects [12] and in the pioneering CBPHC field project at Gadchiroli, India, conducted by SEARCH $[13,14]$ or through retrospective measurements obtained from maternal birth histories $[15,16]$. Verbal autopsy methods have been used to assess the leading causes of child deaths in the project area and whether or not the cause of death "structure" has changed over time [17]. Finally, communities have been consulted during the project planning phase as well as at the time of project evaluation. In these circumstances, community members assist with data collection for structured surveys and participate as key informants or participants in focus group discussions. 


\section{Strategies for community engagement}

Community engagement takes many forms and is commonly mentioned in the assessments included in our database (Table 1). Village health committees are often formed if they were not previously in existence, and projects work with them in project design, implementation and evaluation. Community leaders, including local religious leaders, are commonly consulted. Communities are often mobilized to participate in health campaigns or to practice key healthy behaviors. Many projects have worked with existing community groups or formed new ones, often women's groups. Activities that empower women are common forms of community engagement, including education and consciousness raising of women as well as formation and support of women's microcredit and savings groups.

Communities are commonly requested to participate in the selection of CHWs and to provide support to them and participate in their supervision. Finally, in some projects, special activities are geared toward engaging fathers, mothers-in-law, traditional healers and local drug sellers. Finally, though not commonly, projects have engaged communities by sharing surveillance and evaluation results. Noteworthy examples of projects with strong community engagement strategies include mobilization of churches in Mozambique [12] and Nigeria [18] and national mobilization of communities and short-term community workers for national health weeks in Sierra Leone [19].

\section{Strategies for education of community-level staff, volunteers, beneficiaries and community members in general}

Assessments of the effectiveness of projects included in our database have adopted many innovative approaches to educating $\mathrm{CHWs}$, beneficiaries, and community members as a whole. Some have used social marketing channels such as radio and posters to convey key messages to the entire community. Others have conveyed health education messages through skits, puppet shows and games that engaged children, mothers, or the entire community. One noteworthy example of this approach is the World Relief child survival project in Cambodia $[20,21]$.

Other approaches involved teaching health education messages to volunteer or paid community workers (who most often are mothers) who then conveyed them to their neighbors at the time of home visits or at meetings of small groups of neighbors. Sometimes projects targeted grandmothers for health education messages since they are respected and influential elders in the community. One particularly innovative educational strategy used in some projects is positive deviance inquiry, usually for addressing childhood undernutrition [22]. With this strategy, mothers of undernourished children in a village learn from the mothers of well-nourished children in the village how they care for their children - not just how they feed them but how they care for them more broadly.

Another approach used by some projects is called Care Groups [23], which involves training a small number of master trainers in a project area with a set of health education messages. These trainers each then train another set of trainers who then train another set. Through this "cascade training" approach, large numbers of peer-to-peer counselors can be trained to convey key messages to every household.

\section{Strategies for health systems strengthening}

Many CBPHC projects carried out health system strengthening activities of various sorts. One of the most common was providing mothers and their families with educational messages about warning signs for serious childhood illness or about pregnancy and childbirth for which care should be sought at a health facility. A stronger health system is one in which people seek care appropriately and, when potentially serious conditions are present, prompt care is sought. This is core feature of the approach known as Community-based Integrated Management of Childhood Illness (C-IMCI), utilized in many child survival projects funded by the US Agency for International Development, often with marked expansions of geographic coverage of key child survival interventions. A publication highlighting a number of these projects has been published [24].

Another approach has been to work with communities to establish emergency transport systems to ensure that mothers and children can access the nearest health facility whenever a complication arises and also ensure that the family can obtain transport at a fixed, fair, and affordable price. These referral systems are sometimes linked to insurance schemes whereby families pay small amounts of money on a regular basis, usually during pregnancy, to cover all or most of the cost of such transport if needed. One such approach has been developed by Curamericas for isolated mountainous communities in Guatemala [25,26]. 
Many projects, while implementing community-based interventions, also engage in activities to strengthen the quality of care provided at primary health care centers or referral hospitals, including the capacity of facilities to accept and care for referrals. This often takes the form of training staff who work there or helping the facility to improve its own stock of drugs and supplies.

Other approaches include improving the quality of the community-based health system itself by providing training to CHWs, by strengthening the supervision provided to CHWs, or strengthening the logistics/drug supply system for CHWs.

\section{Strategies for use of community health workers}

Community-based programs often rely on various types of CHWs - trained volunteers or more formally trained and paid workers who can implement specific interventions aimed at improving MNCH. The projects in our database engaged a broad variety of CHWs. For some projects, the training lasted only a few hours or days while for others CHWs had one year or more of full-time formal training. Some CHWs received only a "per diem" payment for attending a training course or a certificate for their service, while others were formally paid government employees. Some CHWs were volunteers or workers who had been engaged for a specific local project or study while others were part of a national government-run program.

Table 2 provides a listing and description of the types of CHWs described by reports in our database.

\section{Strategies for implementation of interventions}

Four types of strategies for implementing interventions were: (1) recognition, referral, and (in certain circumstances) treatment of serious childhood illness by mothers and/or CHWs; (2) routine systematic visitation of all homes, (3) facilitator-led participatory women's groups; and (4) provision of health services at community outreach points by mobile teams from peripheral facilities.

\section{Community case management: recognition, referral, and (when possible) treatment of serious childhood illness by mothers and/or trained community agents}

The review identified considerable evidence regarding the effectiveness of training and supervising CHWs to teach pregnant women and their families about danger signs during pregnancy and childbirth, during the newborn period, and among sick children [27-29]. CHWs can learn to recognize danger signs and they can teach these to mothers, other caregivers, and family members.

Some projects that were effective in improving neonatal and child health also trained and supported CHWs to manage these conditions themselves (or in some cases these CHWs also taught mothers how to treat these conditions). This requires, in addition to proper training, appropriate supervision and logistical support for medications and other supplies [30-33]. The community-based treatment modalities included administration of oral (and in a few cases intramuscular) antibiotics [34], administration of oral rehydration fluids, provision of highly nutritious foods available locally or commercially prepared (known as ready-to-use therapeutic foods, or RUTF), and in some cases provision of micronutrients such as iron, vitamin A and zinc. When community-level workers did not have the capacity to treat children with acute

Table 2. Specific examples of community health workers (CHWs) utilized in community-based primary health care (CBPHC) projects with evidence of effectiveness in improving neonatal and child health

\begin{tabular}{|c|c|c|}
\hline Categony of CHW & Names given to CHW's In thIS category & Comment \\
\hline $\begin{array}{l}\text { Intermittent use of minimally trained } \\
\text { unsalaried workers for highly specific, } \\
\text { targeted activities }\end{array}$ & Child Health Day volunteer & $\begin{array}{l}\text { May receive a per diem pay- } \\
\text { ment }\end{array}$ \\
\hline $\begin{array}{l}\text { Use of unsalaried workers for regular } \\
\text { ongoing activities }\end{array}$ & $\begin{array}{l}\text { Promoters, peer educators, malaria or nutrition agents, Care Group volun- } \\
\text { teers, animators, community case management workers, nutrition coun- } \\
\text { selor mothers, bridge-to-health teams, family health workers, community } \\
\text { surveillance volunteers, female community health volunteers }\end{array}$ & $\begin{array}{l}\text { May receive certain incentives } \\
\text { such as uniforms, per diem } \\
\text { payment for training, or an oc- } \\
\text { casional small stipend }\end{array}$ \\
\hline $\begin{array}{l}\text { Use of workers with } 1-11 \text { months of } \\
\text { training who receive a salary }\end{array}$ & $\begin{array}{l}\text { Health agents, community health agents, family planning agents, health } \\
\text { surveillance assistants, accompagnateurs, lead mothers, soccoristas, Care } \\
\text { Group facilitators (animators or promoters) }\end{array}$ & \\
\hline $\begin{array}{l}\text { Use of workers with } 1 \text { year or more of } \\
\text { training who are salaried }\end{array}$ & Auxiliary nurses, community health officers, health extension workers & \\
\hline
\end{tabular}


illness, they informed mothers and caretakers that urgent treatment at a referral health facility was needed. A comprehensive manual for community-based diagnosis and treatment of serious childhood illness is available for general use [35]. Integrated community case management (iCCM) for childhood illness is now being scaled up in many countries [36].

\section{Routine systematic visitation of homes}

Routine systematic visitation of homes makes it possible to identify those in need of basic services and to provide everyone in the program population with essential health education and selected key services, particularly during pregnancy and the early neonatal period. Community-level workers who make home visits are generally able to identify pregnant women and mothers of young children, provide education to them and other family members (especially husbands and mothers-in-law), recognize danger signs during pregnancy and childhood illness, encourage referral when danger signs are present, and provide treatment for certain conditions that can be identified at the time of home visits such as growth faltering, diarrhea, pneumonia, and malaria.

Based on current evidence, the World Health Organization and UNICEF recommend that all pregnant women receive two home visits during the prenatal period, one home visit during the first 24 hours after birth, and at least one visit as soon as possible after delivery [37]. Activities that should take place during these visits include the following: education about proper nutrition, promotion of antenatal care, education about danger signs during pregnancy and childbirth, promotion of breastfeeding immediately after birth, prevention of hypothermia, and measurement of the weight of newborns to identify low-birthweight newborns who need additional home visits. A number of studies have highlighted the difficulties many women face in accessing health facilities due to distance and cost [38]. Home visitation provides an alternative for those without ready access to health facilities.

Home visitation is also an effective means of providing counseling about breastfeeding and appropriate complementary feeding, hand washing, prevention and treatment of diarrhea, detection and treatment of childhood pneumonia, and family planning services. There are a number of variations of home visitation strategies using community-level workers, from weekly home visits for providing micronutrients to children [39] to regular monthly visitation of all homes in a program population as part of a more comprehensive approach to delivering basic services to the entire population [40].

Finally, an ongoing program of home visitation provides a foundation of trust and awareness. When children develop signs of serious illness that can be managed by CHWs (such as for pneumonia, diarrhea or malaria), families will be more predisposed to contact the CHW for early and prompt treatment.

\section{Participatory women's groups}

Participatory women's groups are led by facilitators with less than two weeks of training who provide the opportunity for further empowerment and education about healthy behaviors, danger signs of serious illness, and proper care of the newborn. These groups may also address issues outside of the health domain that are a priority to the community and that may also have an indirect effect on health (such as income generation activities). These groups may also provide a vehicle for counseling about breastfeeding, birth spacing, infant feeding, hand washing, prevention and treatment of diarrhea, signs of childhood pneumonia, and danger signs during pregnancy and childbirth. Participatory women's groups also can be effective for assisting mothers to rehabilitate malnourished children detected through growth monitoring.

The literature illustrates several effective approaches to facilitating participatory women's groups, including the use of a participatory action-learning cycle [41,42], formation of Care Groups (10-15 women volunteers who meet with a facilitator (promoter/animator) once a month to learn a key health education message to disseminate to each of the mothers in the 10-15 households surrounding each volunteer) [43,44], and education sessions led by community mobilizers [45].

\section{Provision of services at satellite clinics, including holding outreach immunization sessions, by mobile teams from peripheral facilities}

Provision of services at satellite clinics, including holding outreach immunization sessions, by mobile teams based at health centers is a common means of community-based outreach. These mobile teams may have a vehicle or more likely a motorcycle, bicycle, horse or donkey, or they may even travel by foot. The provision of immunization services by mobile health teams at points beyond a peripheral health fa- 
cility is now well-developed in many low-income countries [46]. Other examples of services that can be provided through outreach include promotion of and provision of family planning services, basic antenatal care, testing for HIV and syphilis, distribution of insecticide-treated bed nets, distribution of medications to prevent or treat malaria, and growth monitoring to detect cases of childhood malnutrition.

One widely implemented variation of this strategy is Child Health Days (or sometimes called Child Health Weeks). Generally occurring twice a year, they usually include some combination of immunization administration, vitamin A supplementation, nutritional monitoring (and referral of malnourished children), and distribution of oral rehydration packets, water-purification tablets, or de-worming tablets $[47,48]$. Services are provided at peripheral outreach points separate from a health center such as at a school or community building or even under a tree, and home visits are often carried out in addition to reach those mothers and children who did not come to the outreach points. These children are often identified on the basis of previously developed household registers.

Table 3 demonstrates which evidence-based child survival interventions can be implemented by which implementation modality. The interventions shown in Table 3 are those which have been identified by the Lives Saved Tool (LiST) for inclusion in program plans for reducing under-5 mortality [49]. A more detailed discussion of these four intervention delivery strategies has been reported elsewhere [50].

\section{Frequency of selected program-related processes}

When program assessments that qualified for the review underwent data extraction, reviewers were asked to describe the degree to which communities were involved in various aspects of the project. Some of the findings are contained in Table 4. These findings demonstrate a high degree of community engagement, both in the maternal as well as the neonatal/child health CBPHC projects. More than three-fourths of the

Table 3. Child health interventions with strong evidence of effectiveness through community-based implementation

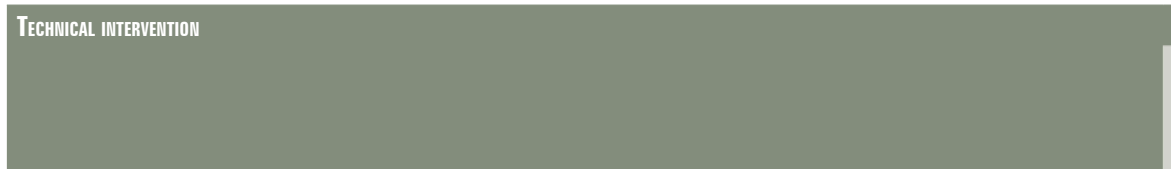

Immunizations: BCG, polio, diphtheria, pertussis, tetanus, measles, Haemophilus Influenza Type b (Hib), pneumococcus, rotavirus immunizations for children; tetanus immunization for mothers and women of reproductive age

Provision of supplemental vitamin A to children 6-59 months of age and to post-partum mothers

Provision of preventive zinc supplements to all children 6-59 months of age

Promotion of breastfeeding immediately after birth, exclusive breastfeeding during the first 6 months of life and continued non-exclusive breastfeeding beyond 6 months

Promotion of appropriate complementary feeding beginning at 6 months of age

Promotion of hygiene (including hand washing), safe water, and sanitation

Promotion of oral rehydration therapy (ORT) for diarrhea with or without zinc supplementation

Promotion of clean deliveries, especially where most births occur at home and hygiene is poor

Detection/referral of pneumonia with or without provision of community-based treatment

Home-based neonatal care (frequent home visits for promotion of immediate and exclusive breast-

feeding, promotion of cleanliness, prevention of hypothermia, and diagnosis and treatment of neo-

natal sepsis by CHW)

Community-based rehabilitation of children with protein-calorie undernutrition through food supple-

mentation (including rehabilitation of children with severe acute undernutrition through ready-to-use

dry therapeutic foods)

Insecticide-treated bed nets (ITNs) in malaria-endemic areas

Indoor residual spraying in malaria-endemic areas

Detection/referral of malaria with or without provision of community-based treatment

Intermittent preventive treatment of malaria during pregnancy (IPTp) and infancy (IPTi) in malariaendemic areas

Detection and treatment of syphilis in pregnant women in areas of high prevalence

Promotion of HIV testing in pregnant women and prevention of mother-to-child transmission (PMTCT) of HIV infection

Iodine supplementation in iodine-deficient areas where fortified salt is not consumed

Provision and promotion of family planning services

Community-Based INTERUENTION DELIVERY STRATEgY

$\begin{array}{cccc}\begin{array}{c}\text { Community } \\ \text { case }\end{array} & \begin{array}{c}\text { Home } \\ \text { visits }\end{array} & \begin{array}{c}\text { Partici- } \\ \text { patory } \\ \text { women's } \\ \text { groups }\end{array} & \begin{array}{c}\text { Out- } \\ \text { reach } \\ \text { services }\end{array} \\ & & \text { soment }\end{array}$

X

$\mathrm{X}$

\begin{tabular}{lllll} 
& & $X$ & & $X$ \\
\hline & $X$ & & $X$ \\
\hline & $X$ & $X$ & $X$ & $X$ \\
\hline & $X$ & $X$ & $X$ & $X$ \\
\hline & $X$ & $X$ & $X$ & $X$ \\
\hline & $X$ & $X$ & $X$ & $X$ \\
\hline & $X$ & $X$ & $X$ & \\
\hline & $X$ & $X$ & $X$ & \\
& & $X$ & $X$
\end{tabular}

*Outreach of health facility staff includes holding mobile clinics and/or immunization sessions at specified locations outside of health facilities in outlying communities on a regular basis. 
Table 4. Community involvement in the implementation of maternal, neonatal and child health CBPHC projects included in the database

\begin{tabular}{|c|c|c|c|c|}
\hline $\begin{array}{l}\text { StAGE OF } \\
\text { IMPLEMENTATION }\end{array}$ & Activity & $\begin{array}{l}\text { PercentaGe OF ASSESSMENTS OF } \\
\text { MATERMAL CBPHC PROJECTS } \\
\text { THAT DESCRIBE ACTIVITY } \\
\text { (N=152) }\end{array}$ & $\begin{array}{l}\text { PERCENTAGE OF ASSESSMENTS OF } \\
\text { MEONATAL AND/OR CHILD HEALTH } \\
\text { CBPHC PROJECTS THAT DESCRIBE } \\
\text { ACTIVITY ( }=548 \text { ) }\end{array}$ & $\begin{array}{l}\text { PERGENTAGE OF ASSESSMENTS OF ALL } \\
\text { MATERNAL, NEONATAL AND/OR CHILD } \\
\text { HEALIH CBPPHC PROJECTS COMBINED } \\
\text { THAT DESCRIBE ACTIUITY ( } \mathrm{m}=\mathbf{7 0 0} \text { ) }\end{array}$ \\
\hline \multirow[t]{3}{*}{ Inputs } & Training of CHWs & 86.3 & 74.0 & 76.6 \\
\hline & Formation and/or support of community groups & 53.6 & 35.5 & 39.5 \\
\hline & Community involvement in planning & 46.4 & 36.1 & 38.3 \\
\hline \multirow[t]{7}{*}{ Processes } & Community involvement in implementation & 90.8 & 78.1 & 80.9 \\
\hline & $\begin{array}{l}\text { Promotion of partnerships between the } \\
\text { community and the health program }\end{array}$ & 73.2 & 53.6 & 57.8 \\
\hline & Promotion of the use of local resources & 74.5 & 53.2 & 57.8 \\
\hline & Promotion of community empowerment & 62.7 & 53.6 & 55.6 \\
\hline & Promotion of leadership in the community & 41.8 & 30.4 & 32.9 \\
\hline & Promotion of women's empowerment & 62.7 & 40.6 & 45.4 \\
\hline & Promotion of equity & 24.8 & 24.8 & 24.8 \\
\hline Evaluation & Community involvement in evaluation & 50.3 & 37.5 & 40.3 \\
\hline
\end{tabular}

projects trained CHWs and more than one-third engaged communities in the formation or support of community groups as well as in the planning of project activities. $81 \%$ of the projects engaged communities in project implementation, and more than half promoted partnerships between the community and the health program, promoted the use of local resources, or promoted community empowerment. Almost half promoted women's empowerment, one-third promoted leadership in the community, and one-quarter promoted equity. $40 \%$ of the projects involved the community in the project evaluation. These findings are highly likely to underestimate the true situation since a large portion of the assessments did not go into this level of detail in describing the community engagement component of the project. Information provided in the assessment was rarely sufficient to provide any deeper understanding of the quality of community engagement or details of how community engagement was actually carried out.

\section{DISCUSSION}

This analysis of strategies used by effective community-based programs for improving MNCH has documented a high degree of community engagement in project implementation. Six categories of strategies were identified: (a) program design and evaluation, (b) community collaboration, (c) education for community-level staff, volunteers, beneficiaries and community members, (d) health systems strengthening, (e) use of CHWs, and (f) intervention delivery. Within each strategy category, community engagement was an essential element for strategy implementation. By its very nature, CPBHC requires community engagement for virtually all aspects of programming. Each of these aspects of community engagement are

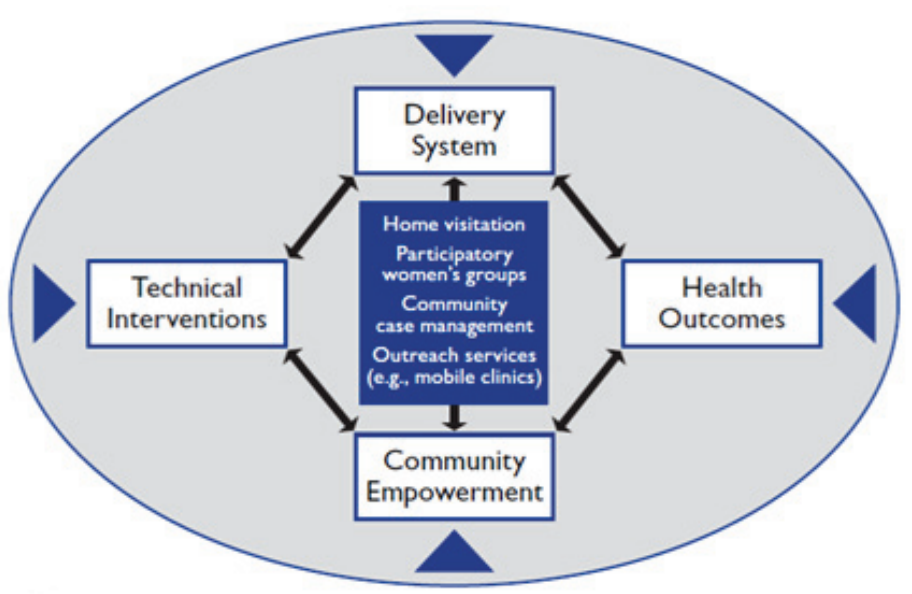

Figure 1. A conceptual framework for planning, implementing and evaluating community-based primary health care programs for improving maternal, neonatal and child health. Blue triangles represent contextual factors. part of the process of building capacity within the community for the benefit of the health program and its capacity to improve the health of mothers, neonates and children. Further elaboration of these strategies as they pertain specifically to maternal, neonatal and child health are discussed in other articles in this series [51-53].

In general, the details of community-based strategies and approaches used by projects to improve $\mathrm{MNCH}$ have not been well described in the peerreviewed scientific literature, where the focus is usually on the health impact of the intervention, or set of interventions, rather than on describing in sufficient detail the exact implementation strategies used to achieve that impact. The findings of this review provide insights into the richness of this dimension of implementation strategies and its importance for program effectiveness. Figure 1 
contains a framework that attempts to capture the importance of community empowerment for improving the health of mothers, neonates and children. The delivery process, along with the technical content of the interventions, is embedded in the eventual health outcomes produced together by the health system working with the community.

The framework in Figure 1 and in fact the strategies identified in this article as well as the interventions identified in other articles in this series all highlight the importance of community engagement and community-based delivery of interventions outside of health facilities in order to reach those who need services. As Gwatkin et al. observed in their 1980 comprehensive review of the effectiveness of programs improving child health and nutrition [54]:

"Unless services reach those in need, even the best-conceived primary health and nutrition care programs can obviously have little impact on mortality. Thus, ... the development of plans for getting services to the people is as important as are decisions concerning which services should be offered."

CBPHC involves, above all, getting services to those who need them.

Figure 1 emphasizes the importance of context. In fact, strategies in general are context-specific. In order for community-based programs to be successful, the context must be carefully considered in order to select the most appropriate combinations of interventions and implementation strategies. Program effectiveness in improving MNCH in a given geographical area requires knowing the local epidemiological priorities (ie, the most frequent and readily preventable or treatable serious conditions) as well as the feasibility of achieving high coverage of evidence-based interventions targeting the epidemiological priorities given the available resources, logistical challenges, contextual constraints (including health system constraints), and available implementation strategies.

The assessments making up our database are derived largely from small demonstration projects, shortterm trials, and efficacy studies of one or a small number of interventions. More independent, rigorous assessments of large-scale integrated programs at scale carried out for five or more years are needed. There are few examples of rigorous assessments of CBPHC at scale over a longer time period. However, these few studies show that the bottlenecks to the effectiveness of large-scale programs include assuring that the number of CHWs and their supervisors is sufficient for the population being served, and that CHWs receive adequate support and supervision, including the basic commodities they need to do their work $[55,56]$. Future research is needed to rigorously assess the effectiveness of community-based approaches at scale in relatively routine conditions [57].

Elsewhere in this series we review the common characteristics of four projects that have long-term evidence of effectiveness [58]. A more in-depth analysis of the strategies and effectiveness of the larger projects included in our review has not been carried out. Although such an analysis would be useful, unfortunately it is beyond the scope of the current series of articles. Questions that might be addressed through such an analysis include:

- Is effectiveness weakened as projects scale up? If not, what specific steps were taken to maintain quality and effectiveness?

- What kinds of community engagement and what kinds of community-level workers were used in different projects, and how did these features contribute to effectiveness?

- What is the contribution of civil society and NGOs to larger-scale projects and how do these contributions affect the effectiveness of public-sector programs?

Health programs need to ensure that local health facilities are appropriately staffed and that the staff has the training, equipment, supplies and transport needed to support community-level work. For example, mobile health teams based at peripheral facilities need, at a minimum, steady supplies of vaccines and adequate transport. Additionally, compassionate and high-quality curative and referral care, including basic hospital and surgical care, lends credibility to the community-based work and the workers who provide it. Small, well-run first-level referral hospitals can be cost-effective in improving health and can serve as an important asset for the community to gain trust in the health system $[59,60]$.

Health systems can benefit greatly from having a community-level worker implement evidence-based interventions in order to achieve high population coverage of these interventions. One recent analysis [61] concluded that almost two-thirds (59\%) of maternal, prenatal, neonatal, and child deaths that could be prevented by all currently available interventions could be prevented with community-based approaches. Facility-based approaches would avert far fewer (20\% at primary health care centers and 22\% at hospitals). 
Of course, the community-level workers who implement these interventions in collaboration with communities must be appropriately trained and supported; a recent Cochrane Review identified the need for adequate and standardized compensation or incentives for CHWs [62]. An effective strategy must be developed for promptly selecting and training new CHWs to replace those who are no longer functioning in this capacity. Although these decisions are normally made by program leaders in consultation with local communities, examples exist in which communities have taken full responsibility for this process [63]. In addition to continuing research on the capability of CHWs to provide specific interventions, more research will be needed on how many interventions a given CHW can take on and what training and supervision are required to maintain quality.

As we have seen in this analysis, empowering the community to be a partner with the health system can help strengthen community-based delivery strategies, as described in Figure 1. The finding supports the recent assertion of Marston et al. [64] that community participation (in which communities work together with health services for the co-production of health care) will be central for achieving the recently released World Health Organization global strategy for women's and children's health [65].

Community case management, routine systematic home visitation, participatory women's groups, and outreach services provided by mobile teams represent important delivery strategies for improving $\mathrm{MNCH}$ in high-mortality, resource-constrained settings. These strategies are not the only approaches to implementing interventions that can improve child health, but they are the most common strategies used in the projects whose assessments are included in our database.

Routine systematic home visitation has the unique advantage of not only delivering key interventions to all who need them but also of ensuring that no one is left out. Marginalization and discrimination of subgroups in high-mortality, resource-constrained settings are not uncommon, leading to many social barriers - in addition to geographic barriers - in accessing services at facilities or even at peripheral outreach points. Thus, for instance, home visits have proven to be an essential strategy for the final stages of polio eradication [66].

Cesar Victora, one of the widely acknowledged leaders of the global movement to improve $\mathrm{MNCH}$, lamented that "We have the bullets [interventions] but not the guns [implementation strategies]" for a second child survival revolution [67]. The analysis provided here helps to point the way forward by identifying implementation strategies used by programs with demonstrated effectiveness.

\section{Study limitations}

The word limits placed on peer-reviewed journal articles make it difficult to fully describe implementation strategies. Our data extraction process was set up to glean whatever information was available regarding these strategies. Our database has been strengthened by the inclusion of 116 assessments that are not peer-reviewed journal articles, and many of them describe their strategies in greater detail. Most of these additional 116 assessments are either unpublished evaluation reports that are publicly available or books. These documents are useful in part because they are not subject to the same space limitations as peer-reviewed articles and can provide more information. Further consolidation and analysis of the extensive and rich evidence about strategies for implementation of CBPHC projects described in the gray literature (including a rigorous examination of the quality of the assessments) would be useful but goes beyond the capacity of the current series of articles to address.

Another limitation of this study is that some of the findings reported here are based on subjective judgments of reviewers. However, the procedure we used - having each assessment reviewed independently by two researchers and then having a third resolve any differences - helps to mitigate this limitation.

A final limitation of our review is the overall difficulty of assessing community participation and engagement. While one of the strengths of our paper is highlighting and further describing the role of the community in implementing effective CBPHC projects, we also note that frameworks and indicators for assessing the quality and effectiveness of this critical dimension of CBPHC were rarely used in the assessments included in our review. Appropriate frameworks and indicators need to be used by future CBPHC projects so that they can more fully describe the role of the community in the process of implementation and better assess the contribution that this made to health outcomes. Useful and more robust approaches to describing and analyzing the process of community participation are available $[68,69]$. 


\section{CONCLUSIONS}

This analysis provides an overview of the ways in which CBPHC projects have planned and evaluated their activities, how they collaborated with communities, how they have used CHWs, and how they have strengthened health systems. The evidence from this review supports the proposition that the application of these strategies can accelerate the decline in maternal, neonatal and child mortality in priority countries. These strategies require that the health system establish functional partnerships with community leaders and community members in order to achieve high levels of coverage of evidence-based interventions. Building the capacity of health systems to work with communities to implement these strategies is one of the priority tasks for ending preventable child and maternal deaths by 2030 .

Using the strategies identified here for strengthening $\mathrm{CBPHC}$ to improve $\mathrm{MNCH}$ can establish an entry point for developing synergies with community-based approaches for the detection and treatment of HIV/ AIDS [70], tuberculosis [71] and malaria [31] as well as for the promotion of family planning services [72], detection and treatment of adult non-communicable diseases [73], and the achievement of universal health coverage. This review supports the growing recognition that community-based programs in high-mortality, resource-constrained settings have a great potential for improving $\mathrm{MNCH}$ at low cost.

Nonetheless, awareness about the full potential of CBPHC is still not yet widespread, and evidence of the effectiveness of CBPHC at scale in priority settings remains limited. Determining the fit and feasibility, within existing local and health systems constraints, of CBPHC implementation strategies for $\mathrm{MNCH}$ interventions is a pressing challenge for national programs. Unleashing the full potential of communities as partners in the process of building effective health systems in high-mortality, resource-constrained settings is one of the great frontiers for global health in the $21^{\text {st }}$ century.

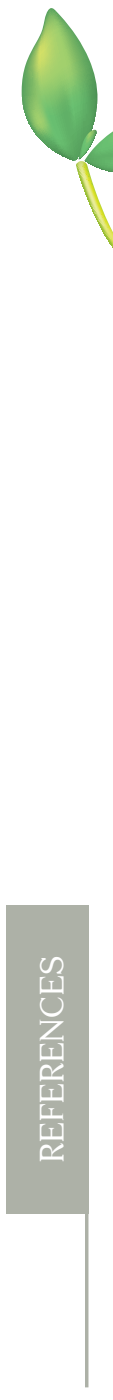

Acknowledgments: We are grateful to Melanie Morrow for her review of an earlier draft of this paper. We are grateful to the following organizations that provided small grants to cover the expenses of this review: UNICEF, the World Bank, the Department of Child and Adolescent Health and Development of the World Health Organization, the CORE Group (Collaboration and Resources for Child Health)/USAID, Future Generations, and the Gates Foundation. We are also grateful to the American Public Health Association and particularly its International Health Section staff, which administered some of these funds. We thank Future Generations for providing office space, administrative support, and salary support to Dr Perry during the initial phase of the review. The World Bank made it possible for one of its consultants, Dr Bahie Rassekh, to participate as a member of the Study Team.

Funding: The following organizations provided funds that were used to conduct the work described in this article: The World Health Organization, UNICEF, the World Bank, the United States Agency for International Development, and the Gates Foundation. The organizations that provided financial support had no role in the execution of the review.

Authorship declaration: HP wrote the first draft. HP, PF, BR, and SG guided this project from the beginning to the end and participated in all decisions related to the overall review. ES and RK performed the analysis of the quantitative data included in our report. All of the authors participated in the revision of earlier drafts and approved the final draft.

Competing interests: All authors have completed the Unified Competing Interest Form at www.icmje.org/coi_ disclosure.pdf (available upon request from the corresponding author), and declare no conflict of interest.

1 World Health Organization, Organisation for Economic Co-operation and Development, World Bank. Effective Aid, Better Health. Geneva: World Health Organization, 2008.

2 Reich MR, Takemi K. G8 and strengthening of health systems: follow-up to the Toyako summit. Lancet. 2009;373:50815. Medline:19150128 doi:10.1016/S0140-6736(08)61899-1

3 Bhutta ZA, Ali S, Cousens S, Ali TM, Haider BA, Rizvi A, et al. Alma-Ata: Rebirth and revision 6-interventions to address maternal, newborn, and child survival: what difference can integrated primary health care strategies make? Lancet. 2008;372:972-89. Medline:18790320 doi:10.1016/S0140-6736(08)61407-5

4 Ekman B, Pathmanathan I, Liljestrand J. Integrating health interventions for women, newborn babies, and children: a framework for action. Lancet. 2008;372:990-1000. Medline:18790321 doi:10.1016/S0140-6736(08)61408-7

5 Rosato M, Laverack G, Grabman LH, Tripathy P, Nair N, Mwansambo C, et al. Community participation: lessons for maternal, newborn, and child health. Lancet. 2008;372:962-71. Medline:18790319 doi:10.1016/S0140-6736(08)61406-3

6 Hill Z, Kirkwood B, Edmond KM. Family and community practices that promote child survival, growth and development: a review of the evidence. Geneva, Switzerland: World Health Organization; 2004. 
7 Bhutta ZA, Darmstadt GL, Hasan BS, Haws RA. Community-based interventions for improving perinatal and neonatal health outcomes in developing countries: a review of the evidence. Pediatrics. 2005;115:519-617. Medline:15866863 doi:10.1542/peds.2004-1441

8 Darmstadt GL, Bhutta ZA, Cousens S, Adam T, Walker N, de Bernis L. Evidence-based, cost-effective interventions: how many newborn babies can we save? Lancet. 2005;365:977-88. Medline:15767001 doi:10.1016/S0140-6736(05)71088-6

9 Bhutta ZA, Ahmed T, Black RE, Cousens S, Dewey K, Giugliani E, et al. What works? Interventions for maternal and child undernutrition and survival. Lancet. 2008;371:417-40. Medline:18206226 doi:10.1016/S0140-6736(07)61693-6

10 Jones G, Steketee RW, Black RE, Bhutta ZA, Morris SS. How many child deaths can we prevent this year? Lancet. 2003;362:65-71. Medline:12853204 doi:10.1016/S0140-6736(03)13811-1

11 Perry H, Rassekh B, Gupta S, Wilhelm J, Freeman P. A comprehensive review of the evidence regarding the effectiveness of community-based primary health care in improving maternal, neonatal and child health: 1. rationale, methods and database description. J Glob Health. 2017;7:010901.

12 Edward A, Ernst P, Taylor C, Becker S, Mazive E, Perry H. Examining the evidence of under-five mortality reduction in a community-based programme in Gaza, Mozambique. Trans R Soc Trop Med Hyg. 2007;101:814-22. Medline:17482222 doi:10.1016/j.trstmh.2007.02.025

13 Bang AT, Bang RA, Tale O, Sontakke P, Solanki J, Wargantiwar R, et al. Reduction in pneumonia mortality and total childhood mortality by means of community-based intervention trial in Gadchiroli, India. Lancet. 1990;336:201-6. Medline:1973770 doi:10.1016/0140-6736(90)91733-Q

14 Bang AT, Bang RA, Reddy HM. Home-based neonatal care: summary and applications of the field trial in rural Gadchiroli, India (1993 to 2003). J Perinatol. 2005;25 Suppl 1:S108-22. Medline:15791272 doi:10.1038/sj.jp.7211278

15 Perry H, Berggren W, Berggren G, Dowell D, Menager H, Bottex E, et al. Long-term reductions in mortality among children under age 5 in rural Haiti: effects of a comprehensive health system in an impoverished setting. Am J Public Health. 2007;97:240-6. Medline:17194853 doi:10.2105/AJPH.2006.088732

16 Johnson AD, Thomson DR, Atwood S, Alley I, Beckerman JL, Kone I, et al. Assessing early access to care and child survival during a health system strengthening intervention in Mali: a repeated cross sectional survey. PLoS One. 2013;8:e81304. Medline:24349053 doi:10.1371/journal.pone.0081304

17 Perry HB, Shanklin DS, Schroeder DG. Impact of a community-based comprehensive primary healthcare programme on infant and child mortality in Bolivia. J Health Popul Nutr. 2003;21:383-95. Medline:15038594

18 Ezeanolue EE, Obiefune MC, Ezeanolue CO, Ehiri JE, Osuji A, Ogidi AG, et al. Effect of a congregation-based intervention on uptake of HIV testing and linkage to care in pregnant women in Nigeria (Baby Shower): a cluster randomised trial. Lancet Glob Health. 2015;3:e692-700. Medline:26475016 doi:10.1016/S2214-109X(15)00195-3

19 Sesay FF, Hodges MH, Kamara HI, Turay M, Wolfe A, Samba TT, et al. High coverage of vitamin A supplementation and measles vaccination during an integrated Maternal and Child Health Week in Sierra Leone. Int Health. 2015;7:26-31. Medline:25316706 doi:10.1093/inthealth/ihu073

20 Relief W. "Light for Life" Child Survival Project, Kampong Cam Province (Cambodia): Final Evaluation (2003-2007). Baltimore, MD: World Relief, 2007.

21 Perry H, Sivan O, Bowman G, Casazza L, Edward A, Hansen K, et al. Averting childhood deaths in resource-constrained settings through engagement with the community: an example from Cambodia. In: Gofin J, Gofin R, editors. Essentials of Community Health. Sudbury, MA: Jones and Bartlett; 2010.

22 Berggren G. Nutritional Education and rehabilitation Program: A Save the Children Project in Vietnam. In: Wollinka O, Keeley E, Burkhalter RB, Bashir N, editors. The Hearth Nutrition Model: Applications in Haiti, Vietnam, and Bangladesh. Wheaton, Il, and Arlington, VA: World Relief and BASICS; 1997.

23 Perry H, Morrow M, Borger S, Weiss J, DeCoster M, Davis T, et al. Care Groups I: An innovative community-based strategy for improving maternal, neonatal, and child health in resource-constrained settings. Glob Health Sci Pract. 2015;3:35869. Medline:26374798 doi:10.9745/GHSP-D-15-00051

24 Ricca J, Kureshy N, Leban K, Prosnitz D, Ryan L. Community-based intervention packages facilitated by NGOs demonstrate plausible evidence for child mortality impact. Health Policy Plan. 2014;29:204-16. Medline:23434515 doi:10.1093/ heapol/czt005

25 Global C. Focused Strategic Assessment: USAID Child Survival and Health Grants Program "Community-Based, ImpactOriented Child Survival in Huehuetenango, Guatemala". 2015. Available: http://www.mcsprogram.org/wp-content/uploads/2016/09/Curamericas_Guatemala_FE.pdf. Accessed: 26 April 2017.

26 Stollak I, Valdez M, Rivas K, Perry H. Casas Maternas in the Rural Highlands of Guatemala: a mixed-methods case study of the introduction and utilization of birthing facilities by an indigenous population. Glob Health Sci Pract. 2016;4:11431. Medline:27016548 doi:10.9745/GHSP-D-15-00266

27 Bang AT, Reddy HM, Deshmukh MD, Baitule SB, Bang RA. Neonatal and infant mortality in the ten years (1993 to 2003) of the Gadchiroli field trial: effect of home-based neonatal care. J Perinatol. 2005;25 Suppl 1:S92-107. Medline:15791283 doi:10.1038/sj.jp. 7211277

28 Baqui AH, El-Arifeen S, Darmstadt GL, Ahmed S, Williams EK, Seraji HR, et al. Effect of community-based newborncare intervention package implemented through two service-delivery strategies in Sylhet district, Bangladesh: a clusterrandomised controlled trial. Lancet. 2008;371:1936-44. Medline:18539225 doi:10.1016/S0140-6736(08)60835-1

29 Kumar V, Mohanty S, Kumar A, Misra RP, Santosham M, Awasthi S, et al. Effect of community-based behaviour change management on neonatal mortality in Shivgarh, Uttar Pradesh, India: a cluster-randomised controlled trial. Lancet. 2008;372:1151-62. Medline:18926277 doi:10.1016/S0140-6736(08)61483-X 
30 Baqui AH, Arifeen SE, Williams EK, Ahmed S, Mannan I, Rahman SM, et al. Effectiveness of home-based management of newborn infections by community health workers in rural Bangladesh. Pediatr Infect Dis J. 2009;28:304-10. Medline:19289979 doi:10.1097/INF.0b013e31819069e8

31 Kidane G, Morrow RH. Teaching mothers to provide home treatment of malaria in Tigray, Ethiopia: a randomised trial. Lancet. 2000;356:550-5. Medline:10950232 doi:10.1016/S0140-6736(00)02580-0

32 Sazawal S, Black RE. Effect of pneumonia case management on mortality in neonates, infants, and preschool children: a meta-analysis of community-based trials. Lancet Infect Dis. 2003;3:547-56. Medline:12954560 doi:10.1016/S14733099(03)00737-0

33 Chowdhury AMR, Cash RA. A Simple Solution: Teaching Millions to Treat Diarrhoea at Home. Dhaka, Bangladesh: University Press Limited; 1996.

34 Coffey PS, Sharma J, Gargi KC, Neupane D, Dawson P, Pradhan YV. Feasibility and acceptability of gentamicin in the Uniject prefilled injection system for community-based treatment of possible neonatal sepsis: the experience of female community health volunteers in Nepal. J Perinatol. 2012;32:959-65. Medline:22422117 doi:10.1038/jp.2012.20

35 CORE Group. Save the Children, BASICS. Community case management essentials: Treating common childhood illnesses in the community. A guide for program managers. Washington, DC: CORE Group; 2010. Available: http://www. coregroup.org/storage/documents/CCM/CCMbook-internet2.pdf. Accessed: 3 April 2017.

36 Young M, Wolfheim C, Marsh DR, Hammamy D. World Health Organization/United Nations Children's Fund Joint Statement on Integrated Community Case Management: an equity-focused strategy to improve access to essential treatment services for children. Am J Trop Med Hyg. 2012;87:6-10. Medline:23136272 doi:10.4269/ajtmh.2012.12-0221

37 WHO. UNICEF. WHO/UNICEF Joint Statement: Home Visits for the Newborn Child: A Strategy to Improve Survival. 2009. Available: http://apps.who.int/iris/bitstream/10665/70002/1/WHO_FCH_CAH_09.02_eng.pdf. Accessed: 26 April 2017.

38 Tanser F, Gijsbertsen B, Herbst K. Modelling and understanding primary health care accessibility and utilization in rural South Africa: an exploration using a geographical information system. Soc Sci Med. 2006;63:691-705. Medline:16574290 doi:10.1016/j.socscimed.2006.01.015

39 Baqui AH, Zaman K, Persson LA, El Arifeen S, Yunus M, Begum N, et al. Simultaneous weekly supplementation of iron and zinc is associated with lower morbidity due to diarrhea and acute lower respiratory infection in Bangladeshi infants. J Nutr. 2003;133:4150-7. Medline:14652364

40 Perry H, Cayemittes M, Philippe F, Dowell D, Dortonne JR, Menager H, et al. Reducing under-five mortality through Hopital Albert Schweitzer's integrated system in Haiti. Health Policy Plan. 2006;21:217-30. Medline:16565151 doi:10.1093/heapol/czl005

41 Prost A, Colbourn T, Seward N, Azad K, Coomarasamy A, Copas A, et al. Women's groups practising participatory learning and action to improve maternal and newborn health in low-resource settings: a systematic review and meta-analysis. Lancet. 2013;381:1736-46. Medline:23683640 doi:10.1016/S0140-6736(13)60685-6

42 Manandhar DS, Osrin D, Shrestha BP, Mesko N, Morrison J, Tumbahangphe KM, et al. Effect of a participatory intervention with women's groups on birth outcomes in Nepal: cluster-randomised controlled trial. Lancet. 2004;364:970-9. Medline:15364188 doi:10.1016/S0140-6736(04)17021-9

43 Perry H, Morrow M, Borger S, Weiss J, DeCoster M, Davis T, et al. Care Groups I: an emerging innovative communitybased delivery strategy for improving maternal, neonatal and child health in high-mortality, resource-constrained settings. Glob Health Sci Pract. 2015;3:358-69. Medline:26374798 doi:10.9745/GHSP-D-15-00051

44 Perry H, Morrow M, Davis T, Borger S, Weiss J, DeCoster M, et al. Care Groups II: a summary of the maternal, neonatal and child health outcomes achieved in high-mortality, resource-constrained settings. Glob Health Sci Pract. 2015;3:37081. Medline:26374799 doi:10.9745/GHSP-D-15-00052

45 Bhutta ZA, Memon ZA, Soofi S, Salat MS, Cousens S, Martines J. Implementing community-based perinatal care: results from a pilot study in rural Pakistan. Bull World Health Organ. 2008;86:452-9. Medline:18568274 doi:10.2471/ BLT.07.045849

46 UNICEF. Tracking Progress in Maternal, Newborn and Child Survival. 2008. Available: http://www.who.int/pmnch/ Countdownto2015FINALREPORT-apr7.pdf/. Accessed:26 April 2017

47 Doherty T, Chopra M, Tomlinson M, Oliphant N, Nsibande D, Mason J. Moving from vertical to integrated child health programmes: experiences from a multi-country assessment of the Child Health Days approach in Africa. Trop Med Int Health. 2010;15:296-305. Medline:20070638 doi:10.1111/j.1365-3156.2009.02454.x

48 Palmer AC, Diaz T, Noordam AC, Dalmiya N. Evolution of the child health day strategy for the integrated delivery of child health and nutrition services. Food Nutr Bull. 2013;34:412-9. Medline:24605691 doi:10.1177/156482651303400406

49 Walker N, Tam Y, Friberg IK. Overview of the Lives Saved Tool (LiST). BMC Public Health. 2013;13 Suppl 3:S1. Medline:24564438 doi:10.1186/1471-2458-13-S3-S1

50 Perry H, Freeman P, Gupta S, Rassekh B. Building on the current evidence to strengthen community-based service delivery strategies for promoting child survival. 2010. Available: http://www.mchip.net/sites/default/files/USAID\%20 CBPHC\%2OFINAL.pdf. Accessed: 3 April 2017.

51 Jennings M, Pradhan S, Schleiff M, Sacks E, Freeman P, Gupta S, et al. Comprehensive review of the evidence regarding the effectiveness of community-based primary health care in improving maternal, neonatal and child health: 2 . maternal health findings. J Glob Health. 2017;7:010902.

52 Sacks E, Freeman P, Sakyi K, Jennings M, Rassekh B, Gupta S, et al. Comprehensive review of the evidence regarding the effectiveness of community-based primary health care in improving maternal, neonatal and child health: 3. neonatal health findings. J Glob Health. 2017;7:010903. 
53 Freeman P, Schleiff M, Sacks E, Rassekh B, Gupta S, Perry H. Comprehensive review of the evidence regarding the effectiveness of community-based primary health care in improving maternal, neonatal and child health: 4 . child health findings. J Glob Health. 2017;7:010904.

54 Gwatkin DR, Wilcox JR, Wray JD. Can health and nutrition interventions make a difference? Washington, DC: Overseas Development Council; 1980.

55 Bryce J, Gilroy K, Jones G, Hazel E, Black RE, Victora CG. The Accelerated Child Survival and Development programme in west Africa: a retrospective evaluation. Lancet. 2010;375:572-82. Medline:20071020 doi:10.1016/S01406736(09)62060-2

56 Azad K, Barnett S, Banerjee B, Shaha S, Khan K, Rego AR, et al. Effect of scaling up women's groups on birth outcomes in three rural districts in Bangladesh: a cluster-randomised controlled trial. Lancet. 2010;375:1193-202. Medline:20207412 doi:10.1016/S0140-6736(10)60142-0

57 Evaluation: the top priority for global health. Lancet. 2010;375:526.

58 Perry H, Rassekh B, Gupta S, Freeman P. Comprehensive review of the evidence regarding the effectiveness of community-based primary health care in improving maternal, neonatal and child health: 7 . shared characteristics of projects with evidence of long-term mortality impact. J Glob Health. 2017;7:010309.

59 McCord C, Chowdhury Q. A cost effective small hospital in Bangladesh: what it can mean for emergency obstetric care. Int J Gynaecol Obstet. 2003;81:83-92. Medline:12676406 doi:10.1016/S0020-7292(03)00072-9

60 Gosselin RA, Thind A, Bellardinelli A. Cost/DALY averted in a small hospital in Sierra Leone: what is the relative contribution of different services? World J Surg. 2006;30:505-11. Medline:16528459 doi:10.1007/s00268-005-0609-5

61 Black RE, Levin C, Walker N, Chou D, Liu L, Temmerman M, et al. Reproductive, maternal, newborn, and child health: key messages from Disease Control Priorities 3rd Edition. Lancet. 2016;388:2811-24.

62 Glenton C, Colvin CJ, Carlsen B, Swartz A, Lewin S, Noyes J, et al. Barriers and facilitators to the implementation of lay health worker programmes to improve access to maternal and child health: qualitative evidence synthesis. Cochrane Database Syst Rev. 2013;8:CD010414. Medline:24101553

63 Special Programme for Research and Training in Tropical Diseases. Community-directed Interventions for Major Health Problems in Africa: A Final Multi-Country Report. Geneva, Switzerland: World Health Organization, 2008.

64 Marston C, Hinton R, Kean S, Baral S, Ahuja A, Costello A, et al. Community participation for transformative action on women's, children's and adolescents' health. Bull World Health Organ. 2016;94:376-82. Medline:27152056 doi:10.2471/ BLT.15.168492

65 WHO. The Global Strategy for Women's, Children's and Adolescents' Health (2016-2030): Survive, Thrive, Transform. 2016. Available: https://www.usaid.gov/sites/default/files/Final-AOTC-file-v2.pdf. Accessed: 3 April 2017.

66 Curry DW, Perry HB, Tirmizi SN, Goldstein AL, Lynch MC. Assessing the effectiveness of house-to-house visits on routine oral polio immunization completion and tracking of defaulters. J Health Popul Nutr. 2014;32:356-66. Medline: 25076672

67 Victora C. Presentation. Global Forum for Health Research; Mexico City2004.

68 Rifkin SB, Muller F, Bichmann W. Primary health care: on measuring participation. Soc Sci Med. 1988;26:931-40. Medline:3388072 doi:10.1016/0277-9536(88)90413-3

69 Molyneux S, Atela M, Angwenyi V, Goodman C. Community accountability at peripheral health facilities: a review of the empirical literature and development of a conceptual framework. Health Policy Plan. 2012;27:541-54. Medline:22279082 doi:10.1093/heapol/czr083

70 Farmer P, Leandre F, Mukherjee JS, Claude M, Nevil P, Smith-Fawzi MC, et al. Community-based approaches to HIV treatment in resource-poor settings. Lancet. 2001;358:404-9. Medline:11502340 doi:10.1016/S0140-6736(01)05550-7

71 Chowdhury AM, Chowdhury S, Islam MN, Islam A, Vaughan JP. Control of tuberculosis by community health workers in Bangladesh. Lancet. 1997;350:169-72. Medline:9250184 doi:10.1016/S0140-6736(96)11311-8

72 Prata N, Vahidnia F, Potts M, Dries-Daffner I. Revisiting community-based distribution programs: are they still needed? Contraception. 2005;72:402-7. Medline:16307960 doi:10.1016/j.contraception.2005.06.059

73 Mishra SR, Neupane D, Preen D, Kallestrup P, Perry HB. Mitigation of non-communicable diseases in developing countries with community health workers. Global Health. 2015;11:43. Medline:26555199 doi:10.1186/s12992-015-0129-5 